\title{
Response of Putative Pathogenicity-related Genes in Tilletia indica Inciting Karnal Bunt of Wheat
}

\author{
M.S. GurJar*, A. Jogawat, M.S. Saharan and R. Aggarwal \\ Fungal and Molecular Biology Laboratory, Division of Plant Pathology, ICAR-Indian Agricultural Research \\ Institute, New Delhi-110012, Delhi, India \\ (Received 15 February 2017; Accepted 14 August 2017; \\ Communicated by J. Kolmer and Á. Mesterházy)
}

\begin{abstract}
Karnal bunt of wheat (Tilletia indica) is an important internationally quarantined disease from food security point of view. For understanding host specificity and host-pathogen interaction, putative pathogenicity-related genes were analysed in Tilletia indica in response to host factor at different time points. Highest radial mycelia growth $(3.4 \mathrm{~cm})$ was recorded in media amended with susceptible host factor followed by resistant host $(2.6 \mathrm{~cm})$ and control $(2.0 \mathrm{~cm})$ at 30 days after incubation significantly. Fourteen homologous sequences of putative pathogenicity-related genes, viz. TiPmk1, TiKss1, TiHog1, TiHsp70, TiKpp2, TiCts1, TiHos2, TiChs1, TiPrf1, TiSid1, TiSsp1, TiSte20, TiUbc4 and TiUkc1, were identified in T. indica by in silico analysis. Some of the pathogenicity-related genes were highly expressed significantly in $T$. indica in response to susceptible host factor as compared to resistant host factor. TiPmk1, TiHogl, TiKss 1 were found highly upregulated up to 26-fold (3 days), 20-fold (3 days) and 18-fold (4 days), respectively, significantly in presence of susceptible host factor. The TiCts 1 and TiChs 1 showed transcripts up to 26-fold (4 days) and 20 -fold ( 3 days) in the presence of susceptible host factor. Further, the TiUbc4 and TiUkc1 were found upregulated up to 20 -fold and 7 -fold at 8 days and 3 days post incubation. This study provided the insight on expression of putative pathogenicity-related genes in $T$. indica which will help in understanding the infection mechanism and basis for further functional genomics approach.
\end{abstract}

Keywords: Tilletia indica, Triticum aestivum, host factor, pathogenicity-related genes, qRT-PCR

\section{Introduction}

Wheat is one of the most important cereal crops of India and worldwide. In recent years, wheat grain quality has been seriously affected due to re-emergence of Karnal bunt disease in India (Gurjar et al. 2016). The disease was first reported from Karnal, Haryana, India (Mitra 1931) and since then, it has been occurring in all major wheat-growing states of north-western India, as well as in other parts of the world like Pakistan, Nepal, Afghanistan, Mexico, Syria, Brazil, USA, Iran and South Africa. Karnal bunt of wheat became an important disease after the introduction of dwarf wheat varieties in North-West

*Corresponding author; E-mail: malkhan_iari@yahoo.com; Phone: +91-25843474 Fax: 011-25840772 
India, where it was of minor importance earlier (Nagarajan et al. 1997). T. indica has become a major sanitary and phytosanitary issue in the wake of the recent Agreement of Agriculture stipulated by the World Trade Organization. Currently, 77 countries have restricted on importing wheat from areas where the disease occurs (Bonde et al. 2004). The wheat importing countries have imposed strict quarantine measures and insist on a zero tolerance limit (Singh and Gogoi 2011). The disease poses an economic threat to the wheat industry due to reduction in grain quality rather than yield (Tripathi et al. 2013). The $T$. indica fungus has a pathogenesis process which infects the host plant at boot stage (S2, Zadok's stage 49) by dikaryotization between compatible mating types. At the maturity of wheat grain, teliospores are liberated during harvesting/threshing to the soil surface or dispersed on or in the grain and the disease cycle begins again (Dhaliwal and Singh 1989). Tilletia indica pathogen is a soil, air and seed borne pathogenic fungus (Carris et al. 2006). Teliospores of T. indica survive in soil up to 5 years. The germination of teliospores is sensitive to temperature and light conditions. Fresh teliospores have a period of dormancy. Exposure of spores to a temperature of $-196{ }^{\circ} \mathrm{C}$ in liquid nitrogen for 15 minutes also provides higher germination (Bansal et al. 1983). The pathogen is genetically highly diverse because of its genetic recombination or mating behaviour between two compatible allantoid sporidia just before infection (Aggarwal et al. 2010).

It is difficult to manage the disease effectively through cultural practices and fungicide application. The best approach to manage the disease is through resistant cultivars. Till now, wheat varieties with durable KB resistance have not been developed. Screening the resistant wheat varieties using many pathogenic isolates of $T$. indica is difficult; thereby identification of resistant and susceptible breeding lines is difficult. Recent studies have indicated that, host defense responsive genes, viz. puroindoline protein PINB (AT_KB2), $\beta$-1, 4-glucanase (AT_KB3), and chitinase (AT_KB7) were highly upregulated in the resistant cultivar (HD 29), whereas the down-regulation of these genes were observed in the susceptible (WL711) cultivar (Tripathi et al. 2013). Till now, genes involved in virulence of $T$. indica have not been studied but few putative pathogenesis-related genes have been characterized in other fungi mainly Ustilago maydis which is a model pathogenic fungus for host-pathogen interaction studies. Pathogenesis-related genes, viz. mating and pathogenic development (Pmk1, Kss1, Kpp2, Ste20); morphology, appressorium development and multi-stress tolerance (Hog 1$)$; protein folding and heat stress tolerance (Hsp 70); cell separation (Cts 1); virulence (Hos 2); dimorphic behaviour sexual development (Chs1), siderophore biosynthesis and pathogenicity (Sid1), the mobilization of storage lipids in spores (Ssp 1), filamentous growth morphogenesis ( Ubc4) and pigment formation ( Ukcl) were isolated and characterized in Ustilago maydis. Tilletia indica and Ustilago maydis are in the same fungal taxonomic group of Basidiomycota and smut and bunt fungi have many similarities. Response of putative pathogenesis genes in T. indica is much needed to understand the infection mechanism of Karnal bunt and for inform any further functional genomics approach. Therefore, we aimed to determine the expression pattern of putative pathogenesis-related genes in T. indica in the presence of host factors (WH 542) and HD 29) using qPCR assay. 


\section{Materials and Methods}

\section{Isolation of Tilletia indica culture and plant material}

The Tilletia indica culture was isolated and established from the teliospore inoculum of infected Karnal bunt of wheat seed (KB-1) using the single spore technique described by Warham (1987). Further, monoteliosporic fungal culture was maintained in agar slants and incubated at $16 \pm 2{ }^{\circ} \mathrm{C}$ temperature in biological oxygen demand (BOD) incubator under alternate light and dark conditions for further study. Two wheat cultivars, resistant (HD 29) and susceptible (WH 542) were collected from Division of Genetics, ICAR-Indian Agricultural Research Institute, New Delhi, India. Cultivars were grown in a growth chamber at $24{ }^{\circ} \mathrm{C} / 18{ }^{\circ} \mathrm{C}$ (day/night cycle), $60 \%$ relative humidity and a photoperiod of $16 \mathrm{~h}\left(212 \mu \mathrm{mol} \mathrm{m} \mathrm{m}^{-2} \mathrm{~s}^{-1}\right.$ photon flux density). Wheat plants were raised up to the boot leaf stage of wheat spike which is most congenial stage for Tilletia indica infection in wheat crop.

\section{Host factors preparation}

Acetone extracts were prepared from resistant (HD29) and susceptible (WH542) cultivars of wheat from tissues of boot leaf stage (Zadok's 49, S2). Spikes (50 g) were ground in liquid nitrogen to a fine powder using pestle and mortar. Ground plant tissues suspended in cold acetone, in the ratio of $1 \mathrm{~g}$ of sample in $10 \mathrm{ml}$ of acetone. The suspension was then agitated in cold condition for 5 hours and filtered through muslin cloth to remove larger debris and stored at $4{ }^{\circ} \mathrm{C}$ in air tight bottles. Acetone was then evaporated at room temperature using rotary evaporator. Finally, the obtained dried material was resuspended in $1 / 10^{\text {th }}$ of the volume of sterilized distilled water and filtered by $0.22 \mu$ filter before adding onto the PDA agar plates (Rana et al. 2001).

\section{Radial mycelial growth of $\mathrm{T}$. indica, minimal media and isolation of total RNA and cDNA}

For fungal mycelia growth, host factor of resistant and susceptible cultivars were spread on PDA plates. Then, mycelial bit $(2 \mathrm{~mm})$ of $T$. indica fungus was inoculated on the PDA plates, and then plates were kept in BOD incubator at $18 \pm 1{ }^{\circ} \mathrm{C}$ to measure radial growth of fungus up to 30 days. Mycelial growth was measured after 0, 4, 8, 15, 20 and 30 days after incubation with two replications and statistically analysed using unpaired $t$-test.

For gene expression analysis, ten percent host factors (resistant and susceptible) were added in $100 \mathrm{ml}$ minimal media in $250 \mathrm{ml}$ conical flask. The $T$. indica mycelial bit were inoculated in supplemented minimal media $\left(0.4 \mathrm{mM} \mathrm{NaCl}, 2.0 \mathrm{mM} \mathrm{KH}{ }_{2} \mathrm{PO}_{4}, 0.3 \mathrm{mM}\right.$ $\left(\mathrm{NH}_{4}\right)_{2} \mathrm{HPO}_{4}, 0.6 \mathrm{mM} \mathrm{CaCl}_{2}, 0.6 \mathrm{mM} \mathrm{MgSO}_{4}, 3.6 \mathrm{mM} \mathrm{FeCl}_{3}, 0.2 \mathrm{mM}$ thiaminehydro chloride, $0.1 \%(\mathrm{w} / \mathrm{v})$ trypticase peptone, $1 \%(\mathrm{w} / \mathrm{v})$ glucose, $5 \%(\mathrm{w} / \mathrm{v})$ malt extract, $2 \mathrm{mM} \mathrm{KCl}, 1 \mathrm{mM} \mathrm{H} \mathrm{BO}_{3}, 0.22 \mathrm{mM} \mathrm{MnSO}_{4} \cdot \mathrm{H}_{2} \mathrm{O}, 0.08 \mathrm{mM} \mathrm{ZnSO}_{4}, 0.021 \mathrm{mM} \mathrm{CuSO}_{4}$, $\mathrm{pH}$ 5.8) and then incubated at $18 \pm 1{ }^{\circ} \mathrm{C}$ in BOD incubator under light and dark conditions up to 15 days. Then, fungus mat harvested at different time points, collected and filtered 
through muslin cloth, followed by washing with sterilized distilled water and immediately stored in $-80{ }^{\circ} \mathrm{C}$ freezer. The different time points were considered for total RNA isolation.

For total RNA isolation, about $0.2 \mathrm{~g}$ fungal tissue was crushed in liquid nitrogen without letting it thaw. The powdered material was transferred to a new tube; immediately $1 \mathrm{ml} \mathrm{RiboZol}{ }^{\mathrm{TM}}$ reagent (Amresco, USA) was added and the mixture was vigorously shaken in order to homogenize the sample, and incubated for $10 \mathrm{~min}$ at room temperature. Two hundred microlitre of chloroform was added per $\mathrm{ml}$ of RiboZol ${ }^{\mathrm{TM}}$ reagent and the tube was vigorously vortexed for $30 \mathrm{sec}$ and incubated at room temperature for $10 \mathrm{~min}$. Following centrifugation $\left(13,000 \mathrm{rpm} ; 15 \mathrm{~min} ; 4^{\circ} \mathrm{C}\right)$, the upper aqueous phase was transferred into a fresh RNase free tube. The RNA of the aqueous layer was precipitated by mixing with 0.7 volumes of isopropyl alcohol; the mixture was incubated for half an hour at $4{ }^{\circ} \mathrm{C}$ and centrifuged $\left(12,000 \mathrm{rpm} ; 10 \mathrm{~min} ; 4^{\circ} \mathrm{C}\right)$. The supernatant was discarded and the RNA pellet was washed twice with $75 \%$ ethanol by dislodging the pellet from the surface of the tube with vigorous shaking followed by centrifugation at 10,000 rpm for $5 \mathrm{~min}$ at $4{ }^{\circ} \mathrm{C}$. Finally, the RNA pellet was dried for $10 \mathrm{~min}$ and dissolved in an adequate volume of DEPC-treated water, before cDNA was synthesized. The cDNA was constructed as follows: $1 \mu \mathrm{g}$ total RNA was used for cDNA synthesis. The reaction was performed using Verso cDNA synthesis kit (Thermo Fisher Scientific, USA): $20 \mu 1$ reaction (5X cDNA synthesis buffer, $5 \mathrm{mM}$ dNTPs mix, RNA primers (500 $\mathrm{ng} / \mu \mathrm{l}$ anchored oligo dT; $400 \mathrm{ng} / \mu \mathrm{l}$ random hexamer), RT enhancer, reverse transcriptase, RNA) was performed using PCR cycling program at $42{ }^{\circ} \mathrm{C}$ for $30 \mathrm{~min}$ (cDNA synthesis), $95^{\circ} \mathrm{C}$ for $2 \mathrm{~min}$.

Table 1. Pathogenicity-related genes used for qPCR assay

\begin{tabular}{|l|l|l|}
\hline \multicolumn{1}{|c|}{ Genes } & \multicolumn{1}{c|}{ Functions } & \multicolumn{1}{c|}{ References } \\
\hline MAP kinase Pmk1 & Mating and pathogenic development & Mayorga and Gold 1999 \\
\hline MAP kinase Ks 1 & Mating and pathogenic development & Muller et al. 2003 \\
\hline MAP kinase Hog1 & Pathogenicity and stress tolerance & Zheng et al. 2016 \\
\hline Hsp70 & Heat stress tolerance & Holden et al. 1989 \\
\hline MAP kinase Kpp2 & Mating and pathogenic development & Muller et al. 1999 \\
\hline Chitinase Cts1 & Cell separation & Langner et al. 2015 \\
\hline Hos2 & Virulence and mating-type genes & Elias-Villalobos et al. 2015 \\
\hline Chitin synthase $C h s 1$ & Mating, virulence and dimorphic & Xoconostle-Cazares et al. 1996 \\
\hline Prf1 & Sexual development & Hartmann et al. 1999 \\
\hline Sid1 & Siderophore biosynthesis & Mei et al. 1993 \\
\hline Dioxygenase Ssp1 & Mobilization of storage lipids & Huber et al. 2002 \\
\hline MAP KKKK Ste20 & Role in mating and pathogenicity & Smith et al. 2004 \\
\hline MAPKK kinase $U b c 4$ & Filamentous growth & Andrews et al. 2000 \\
\hline Protein kinase $U k c 1$ & Morphogenesis and pathogenicity & Durrenberger and Kronstad 1999 \\
\hline
\end{tabular}


In silico identification of putative pathogenicity-related genes

The fourteen putative pathogenicity related genes in $T$. indica (Table 1) were identified from Ustilago maydis based on putative functions. These putative genes were explored by BLASTn search in the Tilletia horrida genome using the U. maydis genes as query using in silico approach. The nucleotide sequences were retrieved from NCBI Genbank and BLAST analysed with Tilletia horrida draft genome (Wang et al. 2015). The most homologous regions of genes were identified for real time-PCR primers and then primers (Table 2) were designed using IDT primer design tool. The designed primers were synthesized from GCC Biotech Pvt., India.

\section{Semi quantitative RT-PCR and quantitative PCR}

Putative pathogenicity-related genes (TiPmk1, TiFus3/Kss1, TiHog1, TiHsp70, TiKpp2, TiCts1, TiHos2, TiChs1, TiPrf1, TiSid1, TiSsp1, TiSte20, TiUbc4 and TiUkc1) were amplified by using PCR in the presence of cDNA sythesized from total RNA extracted from

Table 2. Primers used in semi-quantitative and quantitative PCR analysis

\begin{tabular}{|c|c|}
\hline Genes & Primers sequences \\
\hline TiPmkl & $\begin{array}{l}\text { F: 5'AACTTATGGAGACCGACATGC3' } \\
\text { R: 5'CGTTGAGTAAGAGGTTTGAGGG3' }\end{array}$ \\
\hline TiKss 1 & $\begin{array}{l}\text { F: 5'ACAATTCAGAGCCCACAGG3' } \\
\text { R: 5'CGATAATCTCTGCCAGGGAAG3' }\end{array}$ \\
\hline TiHogl & $\begin{array}{l}\text { F: 5'TCGTACTTTTGCCAGGTCAG3' } \\
\text { R: 5'TCTGAAGATCTGCGACTTTGG3' }\end{array}$ \\
\hline TiHsp70 & $\begin{array}{l}\text { F: 5'TCAATACCAAGAGTCAGCGG3' } \\
\text { R: 5'GACTCGTATTCCCAAGGTTCAG3' }\end{array}$ \\
\hline TiKpp2 & $\begin{array}{l}\text { F: 5'TCATGACCGAATACGTTGCC3' } \\
\text { R: 5'ATCTCGACCAGAATGCAGC3' }\end{array}$ \\
\hline TiCts 1 & $\begin{array}{l}\text { F: 5'ACTCCCAGTCCACGTCTAG3' } \\
\text { R: 5'ACATACTCTCCCCATTTCGC3' }\end{array}$ \\
\hline TiHos 2 & $\begin{array}{l}\text { F: 5'GACTGTCCCGTCTTTGATGG3' } \\
\text { R: 5'AAAGCTTCCTGCACACCGT3' }\end{array}$ \\
\hline TiChs 1 & $\begin{array}{l}\text { F: 5'CAGAACTTCGAGTACAAGATCAGTAACA3' } \\
\text { R: 5'TTCTCCCTTGAAGTAGGATGCA3' }\end{array}$ \\
\hline TiPrf1 & $\begin{array}{l}\text { F: 5'CCATCAAGGACTCTTCCGC3' } \\
\text { R: 5'TTCTTGATGTTGAGCTCCTCG3' }\end{array}$ \\
\hline TiSid1 & $\begin{array}{l}\text { F: 5'GTAACCATGATCTTCCGAGCCA3' } \\
\text { R: 5'CGGACGACGGAGTAGTTGGT3' }\end{array}$ \\
\hline TiSspl 1 & $\begin{array}{l}\text { F: 5'CAACCAGCACTCCTCTTATCTCGAT3' } \\
\text { R: 5'CGGTTGAGGGTGGCATCAT3' }\end{array}$ \\
\hline TiSte20 & $\begin{array}{l}\text { F: 5'AGTACCTCCACAATGAAGGCA3' } \\
\text { R: 5'TCTCCTTTGGCCATCTCGAT3' }\end{array}$ \\
\hline TiUbc4 & $\begin{array}{l}\text { F: 5'TTGCACAATGTTGGGATGCT3' } \\
\text { R: 5'ATCGGCGCTGGATCGTTC3' }\end{array}$ \\
\hline TiUkcl & $\begin{array}{l}\text { F: 5'GTGGATGAAGCCGAGCTTGT3' } \\
\text { R: 5'CGCTTCAGAAGAGCGAGATGTT3' }\end{array}$ \\
\hline
\end{tabular}


T. indica treated with host factors. The following program was used in PCR (BioRad system, 96-wells plates): initial denaturation at $95^{\circ} \mathrm{C}$ for $10 \mathrm{~min}, 40$ cycles of denaturation $95{ }^{\circ} \mathrm{C}$ for $30 \mathrm{sec}$, annealing $60{ }^{\circ} \mathrm{C}$ for $30 \mathrm{sec}$, extension at $72{ }^{\circ} \mathrm{C}$ for $30 \mathrm{sec}$ and final extension at $72{ }^{\circ} \mathrm{C}$ for 2 min. RPS 17 was used as internal control which showed equal expression at all time points.

Pathogenicity genes were analysed for gene expression level at different time points with two biological replicates using two-step qPCR. The qPCR conditions were standardized for the ideal Tm using gradient PCR for each selected gene. The following cycles were used in the real time PCR thermal cycler: pre-incubation at $95{ }^{\circ} \mathrm{C}$ for $10 \mathrm{~min}$, denaturation $95^{\circ} \mathrm{C}$ for $15 \mathrm{sec}$, annealing and extension at $60^{\circ} \mathrm{C}$ for $1 \mathrm{~min}, 40$ cycles of amplification. The threshold $\left(\mathrm{C}_{\mathrm{T}}\right)$ values were automatically calculated; the transcript levels were normalized against internal control RPS17 gene expression in case of T. indica and the fold changes were calculated based on the non-treated control. The SYBR green was used as a detection dye. Each $20 \mu \mathrm{l}$ reaction were mixed well and the real time-PCR analysis was carried out. After 40 cycles, the specificity of the amplifications was verified by melting from 60 to $95{ }^{\circ} \mathrm{C}$, resulting in melting curves. Gene expression in T. indica were normalized by subtracting the mean reference gene i.e. $R P S 17 \mathrm{C}_{\mathrm{T}}$ value from their $\mathrm{C}_{\mathrm{T}}$ value $\left(\Delta \mathrm{C}_{\mathrm{T}}\right)$. The fold change values were calculated using the expression, where $\Delta \Delta \mathrm{C}_{\mathrm{T}}$ represents $\Delta \mathrm{C}_{\mathrm{T}}$ condition of target gene $-\Delta \mathrm{C}_{\mathrm{T}}$ control gene. The fold expression was calculated according to the $2-\Delta \Delta \mathrm{C}_{\mathrm{T}}$ method mentioned by Schmittgen and Livak (2008) and statistically analysed using unpaired $t$-test.

\section{Results}

Radial mycelial growth of Tilletia indica

Mycelia growth of $T$. indica (KB-1 isolate) media amended with host factors showed clear differentiation at 8 days after incubation (DAI) (Fig. 1) as compared to control. Radial growth was found significant ( $p$-value $<0.002$ ), i.e. $1.3 \mathrm{~cm}, 1.1 \mathrm{~cm}, 0.95 \mathrm{~cm}$ in SHF, RHF and control, respectively, at 8 DAI. Finally, radial mycelial growth was recorded significantly as $3.4 \mathrm{~cm}, 2.6 \mathrm{~cm}, 2.0 \mathrm{~cm}$ in SHF, RHF and control, respectively, after 30 DAI. Highest mycelial growth $(3.4 \mathrm{~cm})$ recorded in the susceptible host factor (WH542) (Fig. 2).

The most homologous regions of pathogenicity-related genes, viz. TiPmk1, TiFus3/ Kss1, TiHog1, TiHsp70, TiKpp2, TiCts1, TiHos2, TiChs1, TiPrf1, TiSid1, TiSsp1, TiSte20, TiUbc4 and TiUkcl (Table 1) were identified based on in silico approach. Differential expression pattern of putative pathogenicity related genes (TiPmk1, TiFus3/Kss1, TiHog1, TiHsp70, TiKpp2, TiCts1, TiHos2, TiChs1, TiPrf1, TiSid1, TiSsp1, TiSte20, TiUbc4 and TiUkcl) showed in the presence of host factor using PCR from synthesized cDNA. Comparatively, most of the genes in T. indica were highly expressed in response to susceptible factors (WH542) rather than resistant host factors (HD29) at different time points $(0,1,3,4,8$ and 15 days $)$. 

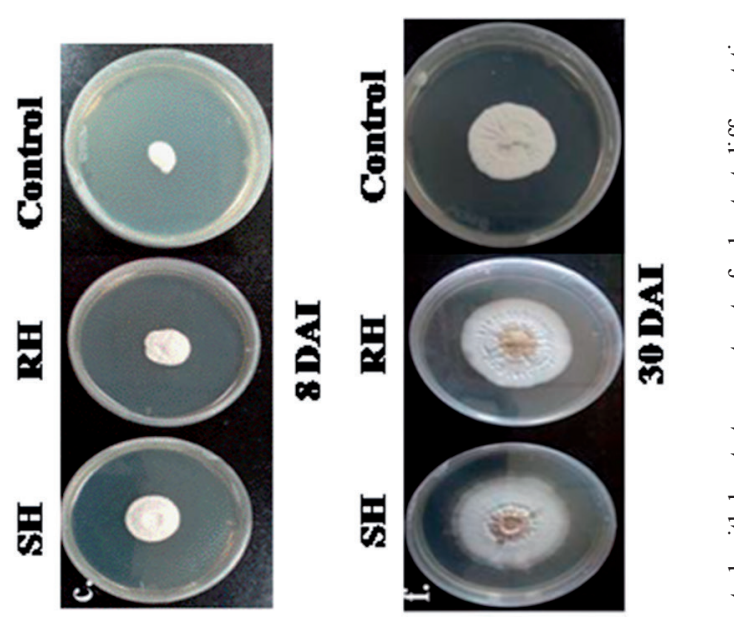

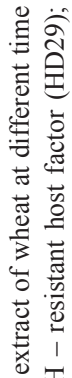
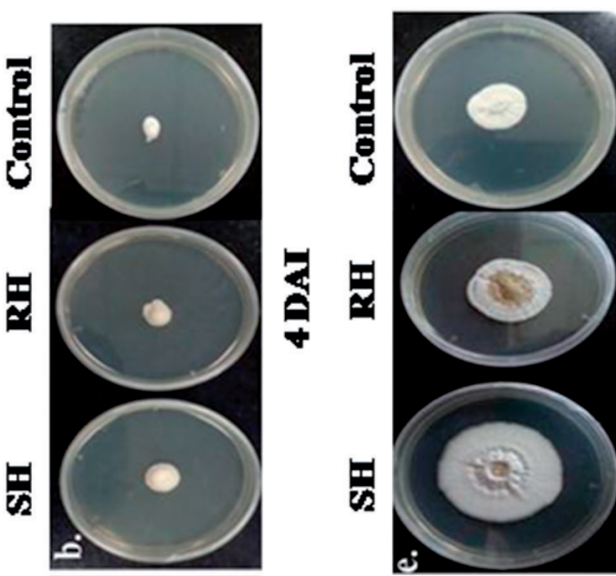

$\operatorname{son}_{0} \frac{1}{2}$

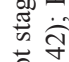

융

刍

3 总

$\stackrel{\square}{2}$

苞

害

苛 仓

营

푼.

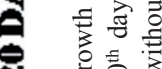

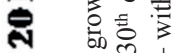

忢出

ఏే

ठㅇ

छ

ㄱ. 궁

这
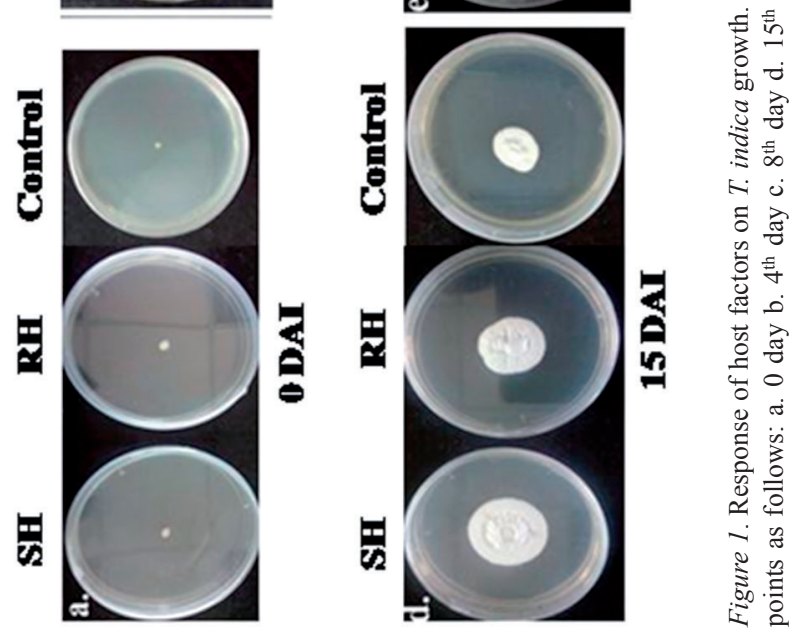

Cereal Research Communications 46, 2018 


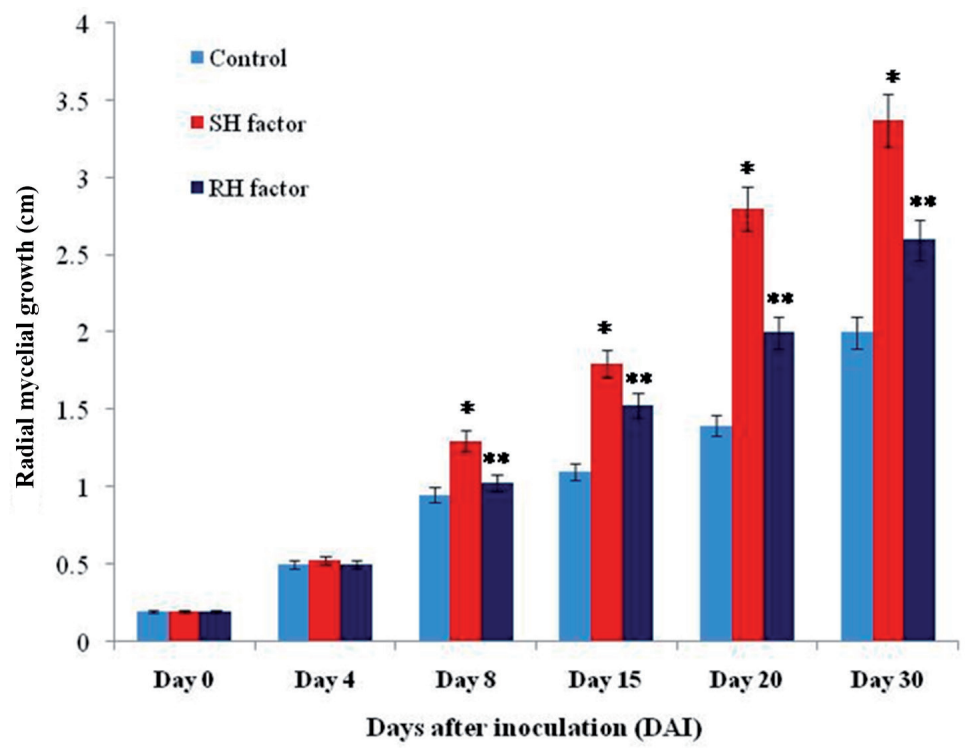

Figure 2. Graph showing radial growth of fungus and days after incubation. The data are shown as mean \pm standard error. [SH - susceptible host factor (WH542); RH - resistant host factor (HD29); Control - without host factor; *significant in susceptible host factor; **significant in resistant host factor]

\section{Relative expression analysis of MAP kinases, metabolism genes and other virulence genes}

Different identified MAP kinase pathway genes (TiPmk1, TiKss1, TiKpp2, TiSte20 and TiHog1) play different role in mating and pathogenic development, morphology, appressorium development and multi-stress tolerance in fungi. Relatively, TiPmk1 gene have shown significantly up-regulation up to 26-fold in transcripts at 3 days in SHF as compared to RHF (13-folds). TiPmk1, TiKss1, TiHog1, TiKpp2 and TiSte20 genes were found significant up regulation in response to SHF (WH542) up to 26-fold (3 days), 18-fold (4 days), 20-fold (3 days), 9-fold (15 days) and 15-fold (3 days) respectively (Fig. 3A, Table $\mathrm{S} 1 *)$. In response to RHF, the relative expression of genes were also found upregulated up to 7.04-fold ( 8 days), 13.34-fold (15 days), 2.12-fold (8 days), 9.11-fold ( 8 days) and 9.52-fold (3 days), respectively. Chitin metabolism related function genes (TiCts 1 and TiChs 1 ) were differentially expressed in presence of host factors. TiCts 1 and TiChs 1 were found upregulated up to 26-fold (4 days) and 20-fold (3 days) (Fig. 3A) in response to SHF. The relative expression of these genes was found upregulated up to 10fold ( 8 days) and 3-fold ( 8 days), respectively, in response to RH factors. Comparatively, TiCts 1 and TiChs 1 genes were highly expressed in T. indica at 3 and 4 DAI in SHF.

Expression of the filamentous growth, morphogenesis and pigment formation genes in T. indica, i.e. TiUbc4 and TiUkc1, respectively, were analysed in response to wheat host

*Further details about the Electronic Supplementary Material (ESM) can be found at the end of the article. 

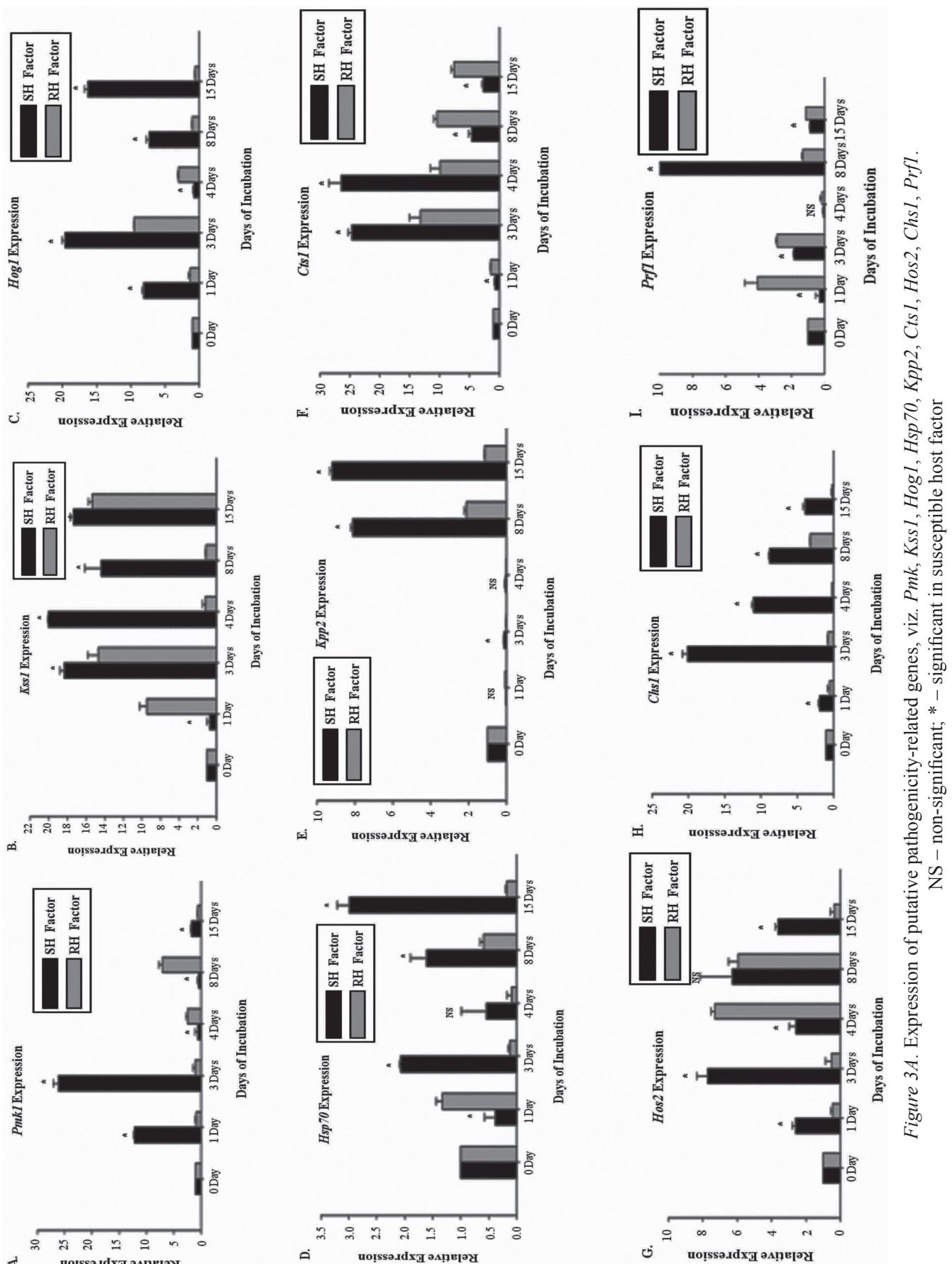

Cereal Research Communications 46, 2018 

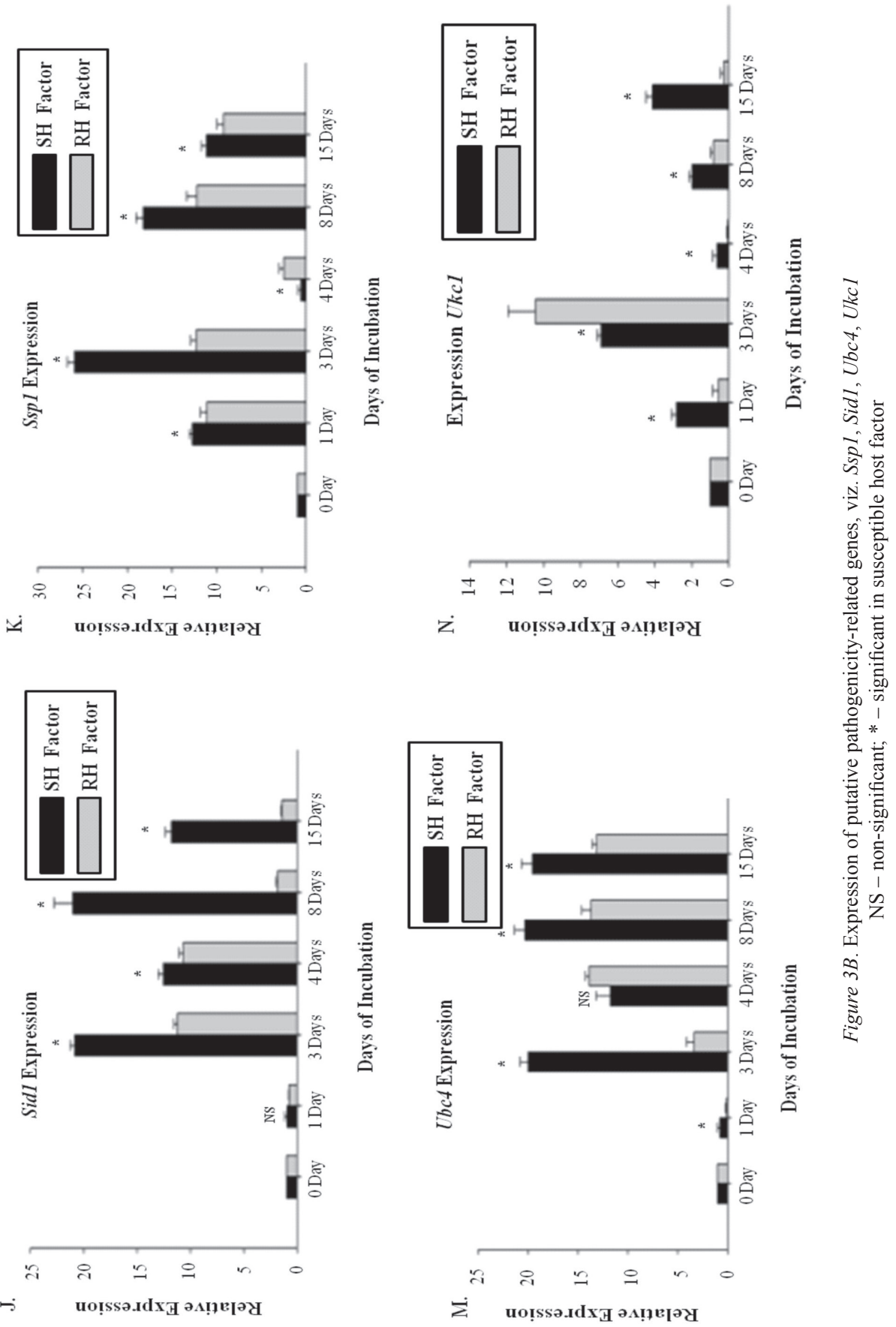

Cereal Research Communications 46, 2018 
using qPCR assay. The TiUbc4 and TiUkcl were found significantly upregulated up to 20-fold (8 days) and 7-fold (3 days) (Fig. 3B) in susceptible. Moreover, TiUkc1 was found to be upregulated up to 10-fold (3 days) in RH factors in correspond to 7-fold (3 days) in SH factors. The genes with diverse functions related to pathogenicity such as virulence (Prf1, Hos 2), siderophore biosynthesis and pathogenicity (Sid1), the mobilization of storage lipids in spores $(S s p 1)$ and protein folding and heat stress tolerance $(H s p 70)$ assessed for transcripts pattern in response to host factors. TiHsp70, TiHos2, TiPrf1, TiSid1 and Tissp1 were found upregulated up to 3-fold (15 days), 8-fold (3 days), 15-fold (8 days), 21-fold (8 days), 26-fold (3 days), respectively (Fig. 3A, B), in response to susceptible factor.

\section{Discussion}

Karnal bunt (Tilletia indica) is one of the major biotic stresses affecting wheat crop as it is re-emerging disease in the North-western plains zone of India. T. indica is a heterothallic fungus in which primary or secondary sporidia or hyphae of compatible mating types must fuse to form dikaryon, at the time of causing infection but the pathogenesis mechanism is poorly understood. Resistance genes have not been identified in wheat against Karnal bunt. Earlier, many studies have been done on pathogenic behaviour and molecular/genetic diversity in the pathogen but the molecular basis of host pathogen interaction (Aggarwal et al. 2010; Thirumalaisamy and Singh, 2012) and of pathogenesis has not been worked out. Host factors may play important role in enhancing the disease potential of $T$. indica which provides signal (s) during morphogenetic development of fungus (Gupta et al. 2012). Therefore, the expression of different pathogenesis-related genes in response to host factors at different time points in vitro using real time PCR assay was investigated.

In the present investigation, host factors extracted from susceptible and resistant wheat cultivars at boot stage (Zadok's 49, S2) were utilized to study their effect on mycelial growth of $T$. indica. The radial growth of $T$. indica recorded in host-factor amended medium showed significantly clear differentiation at 8 days after incubation (DAI). After 30 DAI, The highest radial growth $(3.4 \mathrm{~cm})$ was observed in the presence of susceptible host factor after. It indicated that host factors may influence Karnal bunt disease development at post-anthesis stage in susceptible genotypes of wheat. Relative expression analysis of eleven genes, viz. TiPmk1 (mating and pathogenic development), TiKss1 (mating and pathogenic development), TiHogl (appressorium, pathogenicity and stress tolerance), TiHsp 70 (protein folding and heat stress tolerence), TiCts 1 (chitinase), TiHos 2 (virulence through direct regulation of mating type gene), TiChs 1 (mating, virulence and dimorphic behaviour), TiSid1 (siderophore biosynthesis and pathogenicity), TiSspl (mobilization of storage lipids in spores), TiSte20 (role in mating and pathogenicity) and TiUbc4 (filamentous growth) were observed to be upregulated after 3 DAI whereas three genes, viz. TiPrf1 (sexual development), TiKpp2 (mating and pathogenic development) and TiUkc1 (morphogenesis, pathogenecity and pigment formation) were significantly differentially expressed between 1 to 8 days after inoculation in the presence of susceptible factor. 
Further, these genes can be used for functional characterization and to identify exact role in virulence of pathogen.

Moreover, MAP kinase genes related to mating and pathogenic development, viz. TiPmk1, TiKss1, TiHog1, TiKpp2 and TiSte20 genes were upregulated in response to susceptible at different time points as compared to resistant factor. Previously, few pathogenicity genes have been identified and characterized in other fungi like M. grisea Hogl homolog OSM1 which is essential for survival because it is required for tolerating desiccation, UV-light, and osmotic stresses (Dixon et al. 1999). MlpHog1 gene may play a role in the infectious growth of Melampsora larici-populina and the response of the fungus to various environmental stresses (Yu et al. 2016).

Mitogen activated signal transduction pathway play a crucial role in development of virulence in pathogens. Through mitogen activated protein kinase (MAPK) pathways, pathogens respond to external stimuli and alter their own features such as cell wall integrity, mating, morphological transition, adaptation to stress factors and generate different virulence levels. In pathogens, the Hogl-type mitogen-activated protein kinase (MAPK) gene is involved in both pathogenesis and the response to various stresses, including osmotic stress. The most conserved function of the Hogl MAP kinase pathway in yeast and filamentous fungi described regulating to hyperosmotic stress (Turra et al. 2014). Teliospores of $T$. indica survive in soil up to 5 years which are exposed to stress conditions in terms of temperature and moisture. The survival of teliospores under stress conditions may be associated with presence of certain genes like TiHogl which have role in pathogenesis and withstanding osmotic stress. In present study also expression of TiHogl along with other genes were analysed at different time points induced by host factor. Presence of wheat host factors showed the high expression of MAP kinases, viz. TiPmk1 and TiKss 1 in T. indica after 7 and 14 days (Gupta et al. 2012). Pmkl was found to be essential for appressorium formation and pathogenicity in various fungal pathogens, viz. Ustilago maydis, M. Grisea (Mey et al. 2002).

In present investigation, chitin metabolism genes like TiChs1 (chitin synthase) and TiCts 1 (chitinase 1) were upregulated in presence of susceptible factor after 3 and 4 days of incubation. In the presence of susceptible host factor, the TiCts 1 and TiChs 1 were also highly expressed showing up to 26.46-fold and 20.14-fold at 4 ad 3 days, respectively. Chitin synthesis as well as breakdown is important for fungal growth and development. Similarly, Chs 1 and Cts 1 genes were found to play important role in pathogenicity of Ustilago maydis (Langner et al. 2015). In this study, TiUbc4 and TiUkc1 in T. indica were differentially expressed in response to host factor. The TiUbc4 gene in T. indica was found to be upregulated in the presence of susceptible factor. It may play role in filamentation and high pigment formation during pathogenesis of T. indica. Earlier researchers reported that the Ubc4 gene encodes a putative MAPKKK which functions upstream of Kpp2 in the same MAP kinase pathway (Andrews et al. 2000). In present study, the genes with diverse functions like virulence (Prf1, Hos 2), siderophore biosynthesis and pathogenicity (Sid1), the mobilization of storage lipids in spores (Sspl) and protein folding and heat stress tolerance (Hsp70) were also studied. TiHsp70 (heat shock protein) was down regulated in both host factors at 3 and 4 days of incubation. Moreover, the TiSsp1, TiHos 2, 
TiSidl genes found to be highly upregulated except TiPrfl in susceptible host (WH 542) at 3 days. In our study in response to susceptible host factors, TiPrfl was found upregulated on $8^{\text {th }}$ day of incubation which suggests that it may play role in pathogenic and mating development in T. indica. Previously, Muller et al. (1999) reported that the reduction in expression of the HMG box transcription factor Prfl in $\Delta k p p 2$ mutants of U. Maydis.

The process of population shifts during developmental stage of $T$. indica accompanied the change in morphology and in turn appearance disappearance of virulence genes on fungal populations. In conclusion, most of the putative pathogenesis-related genes in Tilletia indica were highly expressed showing higher transcripts in susceptible host factor. Further, some genes, viz. TiHog1, TiPmk1, TiKss1, TiCts1 and TiUkc1 can be utilized to identify function in relation to pathogenesis and to understand infection mechanism of T. indica. In addition, it will provide basis for further functional genomics to unravelling infection mechanism of Tilletia indica fungus in context to host resistance of Karnal bunt disease.

\section{Acknowledgements}

We gratefully acknowledge research grant from ICAR-Consortium Research Platform on Genomics (12:151/2015) for funding of this research work. We are also thankful to Director and Joint Director (Research), ICAR-IARI, New Delhi for providing guidance and facilities.

\section{References}

Aggarwal, R., Tripathi, A., Yadav, A. 2010. Pathogenic and genetic variability in Tilletia indica monosporidial culture lines using universal rice primer-PCR. Euro. J. Plant Pathol. 128:333-342.

Andrews, D.L., Egan, J.D., Mayorga, M.E., Gold, S.E. 2000. The Ustilago maydis ubc4 and ubc5 genes encode members of a MAP kinase cascade required for filamentous growth. Mole. Plant Microbe. Inter. 13:781-786.

Bansal, R., Singh, D.V., Joshi, L.M. 1983. Germination of teliospores of Karnal bunt of wheat. Seed Res. 11:258-261.

Bonde, M.R., Berner, D.K., Nester, S.E., Peterson, G.L., Olsen, M.W., Cunfer, B.M., Sim, T. 2004. Survival of Tilletia indica teliospores in different soils. Plant Dis. 88:316-324.

Carris, L.M., Castlebury, L.A., Goates, B.J. 2006. Nonsystemic bunt fungi-Tilletia indica and T. horrida: a review of history, systematics, and biology. Annu. Rev. Phytopathol. 44:113-133.

Dhaliwal, H.S., Singh, D.V. 1989. Production and interrelationship of two types of secondary sporidia of Neovossia indica. Curr. Sci. 58:614-618.

Di Pietro, A., Garcia-Maceira, F.I., Meglecz, E., Roncero, M.I.G. 2001. A MAP kinase of the vascular wilt fungus Fusarium oxysporum is essential for root penetration and pathogenesis. Mole. Microbiol. 39:11401152 .

Dixon. K.P., Xu, J.R., Smirnoff, N., Talbot, N.J. 1999. Independent signaling pathways regulate cellular turgor during hyperosmotic stress and appressorium-mediated plant infection by Magnaporthe grisea. Plant Cell 11:2045-2058.

Durrenberger. F., Kronstad, J. 1999. The $u k c 1$ gene encodes a protein kinase involved in morphogenesis, pathogenicity and pigment formation in Ustilago maydis. Mole. Gen. Genet. 261:281-289.

Elias-Villalobos, A., Fernandez-Alvarez, A., Moreno-Sanchez, I., Helmlinger, D., Ibeas, J.I. 2015. The Hos2 Histone deacetylase controls Ustilago maydis virulence through direct regulation of mating-type genes. PLoS Pathol. 11:e1005134. 
Gupta, A.K., Seneviratne, J.M., Joshi, G.K., Kumar, A. 2012. Induction of MAP kinase homologues during growth and morphogenetic development of Karnal bunt (Tilletia indica) under the influence of host factor (s) from wheat spikes. The Scientific World J. 12:1-12.

Gurjar, M.S., Jogawat, A., Kulshresta, D., Sharma, S., Gogoi, R., Aggarwal, R. 2016. Intraspecific variation of Tilletia indica isolates causing Karnal bunt of wheat in India. Indian Phytopathol. 69:352-356.

Hartmann, H.A., Kruger, J., Lottspeich, F., Kahmann, R. 1999. Environmental signals controlling sexual development of the corn smut fungus Ustilago maydis through the transcriptional regulator Prf1. The Plant Cell 11:1293-1305.

Holden, D.W., Kronstad, J.W., Leong, S.A. 1989. Mutation in a heat-regulated hsp 70 gene of Ustilago maydis. The EMBO J. 8:1927.

Huber, S.M.F.E., Lottspeich, F., Kamper, J. 2002. A gene that encodes a product with similarity to dioxygenases is highly expressed in teliospores of Ustilago maydis. Mole. Genet. Genom. 267:757-771.

Langner, T., Ozturk, M., Hartmann, S., Cord-Landwehr, S., Moerschbacher, B., Walton, J.D., Gohre, V. 2015. Chitinases are essential for cell separation in Ustilago maydis. Eukar. Cell 14:846-857.

Mayorga, M.E., Gold, S.E. 1999. A MAP kinase encoded by the $u b c 3$ gene of Ustilago maydis is required for filamentous growth and full virulence. Mole. Microbiol. 34:485-497.

Mei, B., Budde, A.D., Leong, S.A. 1993. Sid1, a gene initiating siderophore biosynthesis in Ustilago maydis: molecular characterization, regulation by iron, and role in phytopathogenicity. Proc. Natl Acad. Sci. 90:903-907.

Mey, G., Oeser, B., Lebrun, M.H., Tudzynski, P. 2002. The biotrophic, non-appressoria forming grass pathogen Claviceps purpurea needs a Fus3/Pmkl homologous MAP kinase for colonization of rye ovarian tissue. Mole. Plant-Microbe Inter. 15:303-312.

Mitra, M. 1931. A new bunt on wheat in India. Annals App. Biol. 18:178.

Muller, P., Aichinger, C., Feldbrugge, M., Kahmann, R. 1999. The MAP kinase kpp2 regulates mating and pathogenic development in Ustilago maydis. Mole. Microbiol. 34:1007-1017.

Muller, P., Weinzierl, G., Brachmann, A., Feldbrugge, M., Kahmann, R. 2003. Mating and pathogenic development of the smut fungus Ustilago maydis are regulated by one mitogen-activated protein kinase cascade. Eukar. Cell 2:1187-1199.

Nagarajan, S., Aujla, S.S., Nanda, G.S., Sharma, I., Goel, L.B., Kumar, J., Singh, D.V. 1997. Karnal bunt (Tilletia indica) of wheat-a review. Rev. Plant Pathol. 76:1208-1214.

Rana, M., Arora, C., Ram, B., Kumar, A. 2001. Floret specificity of Karnal bunt infection due to presence of fungal growth-promotory activity in wheat spikes. J. Plant Biol. 28:283-290.

Schmittgen, T.D., Livak, K.J. 2008. Analyzing real-time PCR data by the comparative CT method. Nature Protocol 3:1101-1108.

Singh, D.V., Gogoi, R. 2011. Karnal bunt of wheat (Triticum sp.): A global scenario. Indian J. Agr. Sci. 81:3-14.

Smith, D.G., Garcia-Pedrajas, M.D., Hong, W., Yu, Z., Gold, S.E., Perlin, M.H. 2004. A ste20 homologue in Ustilago maydis plays a role in mating and pathogenicity. Eukary. Cell 3:180-189.

Thirumalaisamy, P.P., Singh, D.V. 2012. Variability of Indian isolates of Tilletia indica assessed by pathogenicity and molecular markers. J. Phytopathol. 160:525-531.

Tripathi A., Aggarwal, R., Yadav, A. 2013. Differential expression analysis of defense related genes responsive to Tilletia indica infection in wheat. Turk. J. Biol. 37:606-613.

Turra, D., Segorbe, D., Di Pietro, A. 2014. Protein kinases in plant-pathogenic fungi: conserved regulators of infection. Annu. Rev. Phytopathol. 52:267-288.

Wang, N., Ai, P., Tang, Y., Zhang, J., Dai, X., Li, P., Zheng, A. 2015. Draft genome sequence of the rice kernel smut Tilletia horrida strain QB-1.Genome Announc. 3:e0621-15.

Warham, E.J. 1987. Studies on Karnal Bunt of Wheat. PhD, University of Wales. Aberystwyth, UK.

Xoconostle-Cazares, B., Leon-Ramirez, C., Ruiz-Herrera, J. 1996. Two chitin synthase genes from Ustilago maydis. Microbiol. 142:377-387.

Yu, D., Li, R., Yu, Z., Cao, Z. 2016. Molecular characterization of a Hog1-type MAPK, MlpHog1, from Melampsora larici-populina. Phytoparasit. 44:251-259.

Zheng, D., Wang, Y., Han, Y., Xu, J.R., Wang, C. 2016. UvHOG1 is important for hyphal growth and stress responses in the rice false smut fungus Ustilaginoidea virens. Sci. Rep. doi:10.1038/ srep24824. 


\section{Electronic Supplementary Material (ESM)}

Electronic Supplementary Material (ESM) associated with this article can be found at the website of CRC at http://www.akademiai.com/content/120427/

Electronic Supplementary Table S1. Fold changes of pathogenicity-related genes in Tilletia indica 